\title{
THE JOURNAL OFPGR
}

\section{PEDAGOGIC PRACTICE \\ AND THE WARWICK}

\section{PGR TEACHING COMMUNITY}

\section{Editorial: PGR Pandemic Pedagogies}

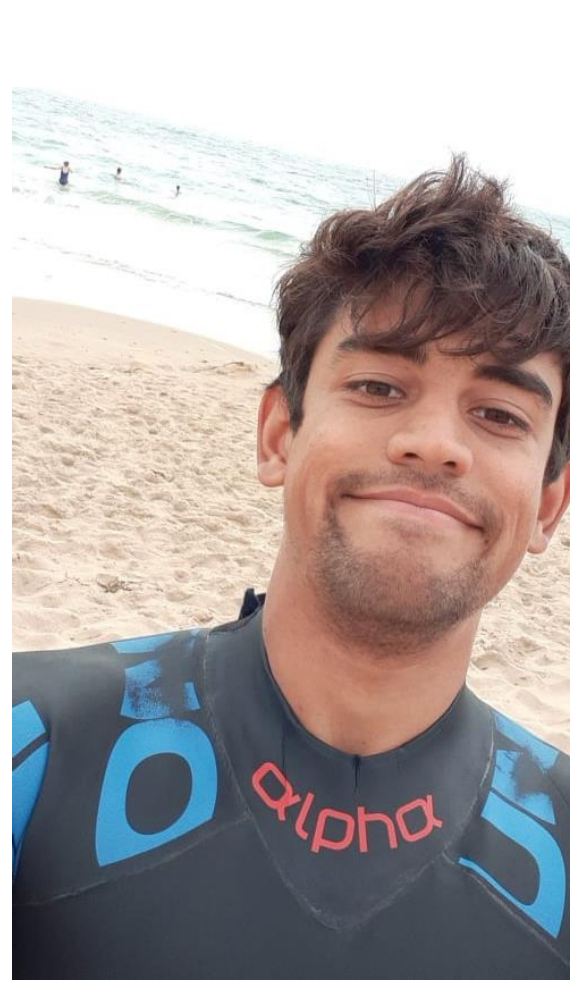

\begin{abstract}
Josh Patel
Early Career Teaching Fellow 2020-21, Institute of Advanced Teaching and Learning, University of Warwick Correspondence: Joshua.patel@warwick.ac.uk Twitter: @JoshPatel_HE

Josh's doctoral research explored the development and change in how it has been imagined universities contributed to liberal society in the post-war period. Josh is interested in developing his research to consider how students and staff navigated higher education opportunities and the various and distinctive learning outcomes they derived from living and learning in higher education. He is particularly interested in pedagogies of care and the importance of space and community to learning. Josh has taught in the History department for two years, is an Associate Fellow of the Higher Education Academy, and head swimming coach at UWSWP.
\end{abstract}

\section{Abstract}

In this editorial, I introduce our pilot launch issue on postgraduate pandemic pedagogies. I explain our rationale for our experimental dialogic journal and outline our ambition through the wider project the journal is a part of. We hope to bring together an organic and self-sustaining community of practice of postgraduate researchers who teach.

Keywords: PGR teacher training, community, peer learning, academic journals, co-creation. 


\section{Hello world!}

Welcome to the pilot issue of the Journal of PGR Pedagogic Practice! The JPPP team and I are absolutely delighted to have been able to bring together some of Warwick's brilliant postgraduate researchers (PGRs) to share some fascinating perspectives on their teaching practice and experiences in higher education. We hope they will be comforting examples and thought-provoking reflections for the wider community of PGRs. To others, we hope they are indicative of the sort of novel pedagogies PGRs have cultivated and the challenges they faced in their teaching during a difficult time for higher education.

Warwick's teaching quality was rated notably highly in the National Student Survey during the pandemic (Warwick, 2021), and PGRs were necessarily an essential component of that. PGRs are rightly coming to be recognised as key to the delivery of teaching in higher education institutions (Fung 2021; UCU 2021). Their precarious position in a 'liminal space' between 'staff' and 'student' means PGRs face considerable and unique challenges. PGRs often lack access and connections to wider institutional, professional, and collegiate opportunities (Schussler, et al. 2015). Those that do exist, such as training courses working toward Associate Fellowship of the Higher Education Academy like the APP PGR at Warwick, are invaluable for PGRs. The benefits derived from training can, however, often be fragile. The self-efficacy of PGRs who teach, their selfbelief in their capacity to deliver teaching, often declines after initial training has concluded (Bandura, 1993; Chuiu and Corrigan, 2019). The wellbeing of PGRs is also notoriously poor (Guthrie et al. 2017).

Yet many PGRs often develop sophisticated and innovative pedagogies and educational philosophies. Others reflect thoughtfully on the successes and failures of their teaching practice at the coalface. There are few regular opportunities for PGRs to share their experiences of teaching with each other or the wider community of practice, especially across disciplines.

We hope therefore, that this pilot issue of this experimental journal might have a part to play in supporting the personal and professional development of PGRs who teach. The aim of the JPPP was to reimagine the role of a journal to best support PGRs. It was proposed that the journal would provide a space maintained by PGRs, for PGRs, as 'peers'. PGRs would regularly come together to exchange, discuss, and review their teaching practice. Realising this volume of JPPP marks some of the very earliest movements towards sustaining such a dialogue and community of practice. Before we get stuck into our PGRs' reflections on their teaching practice, I'd like to reflect a little on the origin and ideals of the JPPP and its place in the wider teaching community.

\section{The Warwick Postgraduate Teaching Community}

The JPPP has its origins in a Warwick International Higher Education Academy (WIHEA) funded student co-creation project at the Academic Development Centre to create a 'Postgraduate Teacher Digital Hub'. The aim was, by working with a number of postgraduates who teach, to foster a community of practice of postgraduates 'for the sharing of pedagogy and practice, mentorship and a resource for teaching in the digital era'. This was intended to be an ongoing community of practice and enhanced by PGR's own work. In February 2021 eight PGRs from a range of disciplines came together as a team of 'PGR Teaching Champions', to begin to tackle this task. In an interesting mirroring of our undergraduate teaching, because of the ongoing lockdowns, all our meetings and work of the team were conducted through Microsoft Teams.

At our earliest meetings in mid-April, the team keenly recognised the importance of supporting PGRs who teach. How we might 
practically support them, at an incredibly difficult time in the midst of the pandemic, was a more difficult question to answer. A 'digital hub' suggested some sort of central shared community 'space', such as those information repositories offered by Warwick's Moodle, or the university's website building service, Sitebuilder. Spaces like Moodle also permit community engagement through the construction of forum spaces.

However, many of the team, including myself, were concerned that building such a space would tend towards a 'one-and-done' information dump. Such a repository of information would tend towards passive learning. The project would have no afterlife, no legacy, and a sterile community with little genuine, sustained peer-engagement. It was felt instead greater long-term support might be found by fostering of a community built around mutual interest in teaching and personal development. Recent research has stressed effective learning requires a community of trust within learning as a relational and emotional process can take place (Yang and Carless 2013; Carless 2013; Steen-Utheim and Wittek 2017; Crossman 2007; Chatterjee and Correia 2020; MirallesArmenteros et al. 2021). Our idea was that postgraduate tutors would be best supported by kickstarting a process of helping postgraduate tutors organise themselves. This community would help reinforce and perpetuate peer-learning (Arnstein 1969; Hilsdon 2014). It would align with institutional objectives to encourage co-creation and to raise standards of teaching (Warwick 2018).

Sustaining a vibrant community of practice would require something more dynamic than just a repository of information. As such, we proposed that the ultimate outcome of the project might be something we called the Warwick Postgraduate Teaching Community (Warwick PTC). This community would, it was hoped, provide a social centre of gravity and in turn perpetuate the sustenance of wider activities to support PGRs in the long run. We aimed to help contribute to the beginning of the infrastructure and architecture of such a community. The team devised a number of project outcomes in order to facilitate this community of practice. There would still be information repositories hosted through digital spaces, like our

Moodle. But these would be accompanied by a number of initiatives to help connect peers, including a buddy system in order to facilitate peer-observation of practice, a regular newsletter, and eventually social events and social media accounts. The team also felt it was important to ascertain what types of support PGRs felt were important. A large portion of the group were involved in producing and disseminating our Survey of PGR Teachers which ran this summer. Some preliminary results of our survey are published in this volume.

The JPPP was a product of this attempt to kick-start the community of practice. We imagined a constructive, cross-disciplinary dialogue to collectively raise the quality of teaching and enhance the outcomes of PGR experiences. With this first edition of the journal, we intended to consider the viability of using a journal as a tool to help PGRs share their practice, learn from each other, and evidence their ongoing commitment to their continuous professional development. The process of advertising our Call for Papers, editing and reviewing submissions, and publishing the journal have, we hoped, contributed to this process. Each of the following papers was firstly put through an editorial review by myself. Secondly, the papers were submitted to a semi-formal anonymised peer review process. In this process, a fellow PGR reviewed the submissions as a true 'peer' and an expert in the practice of being a PGR who teaches. Their expert opinion, perspective, and advice was invaluable in ensuring that the pieces spoke to PGR teaching practice and might be most helpful and useful to other PGRs. This process was, I hope, constructive for everyone involved. I have certainly myself had the pleasure to have stimulating and thoughtprovoking conversations with a wide range of PGRs, thoughts I've taken forwards in the development of my teaching practice. 


\section{PGR Pandemic Pedagogies}

After nearly two years of disruption caused by the pandemic, there was little else that our pilot issue could use as its central theme. We asked submitters to consider what unique 'PGR Pandemic Pedagogies' had emerged as they faced these challenges. We thought it was important for PGRs to see where their efforts in tackling these problems had not been successful, and to consider what they had learned from their failures. We thought that this sort of reflection would have been especially valuable for the development of their teaching practice, but also for other PGRs to hear about themselves. We were curious particularly as to how PGRs might consolidate the benefits of these experiences once universities pivot back to face-to-face teaching and learning, and what challenges still needed to be overcome.

We were delighted with the extremely interesting, varied, and thoughtful the submissions we received. To best sustain a dialogue, we have preferred succinctness over length, and most pieces in this first volume are sort critical reflections of $800-2500$ words. Often these pieces are modelled on the 'Narrative of Professional Practice' as part of the work needed for accreditation for Associate Fellowship of the Higher Education Academy. They engage with the pedagogic literature and contain experimental new practices, handy tips for budding teachers, a refreshing eye on established practices, and accounts of valuable lessons learned. Some are more informal but still critical and reflective pieces. Many contain invaluable narratives of failure and experiments that didn't work. Without this journal, these accounts would probably have remained private experiences. The benefits that other PGRs in similar positions and facing similar problems might have gained would have been lost.

As our team found, the potential insights derived from comparing and contrasting the signature pedagogies of different disciplines can productively inform teaching practice. We invited submissions from PGRs from across all disciplines and were delighted to receive submissions from across the sciences, humanities, and social sciences, and from a range of students, including experienced and new PGRs and of a wide age range. Our contributions cover the role of PGRs in traditional seminar teaching and lecturing but also practical labs. This mix of experience has been illuminating, particularly as the pandemic forced PGRs to look again at their teaching practices. It ranges from Matteo Mazzamurro's reflection on his seminar teaching and how his understanding of space was shifted by the pandemic, and Joy Oti's rethinking of Problem-Based Learning, to Liz Bishop's narrative of how she bought in her research in 3D printing to assist in the securing a safe face-to-face learning environment when her labs learning activities could not be migrated online. Daniela Sordillo takes these reflections further and applies them to PGR learning and considers her attempt to reimagine poster sessions for PGR researchers. Alice King draws on her research on student attitudes to sexual violence and her experience at two different higher education institutions to compare the performance of masculinity in seminars, and the problems it poses for her teaching. We have even managed to provide a reflection not just across disciplines but across the supposedly sharp divide between secondary education and higher education, thanks to lan Hamilton. lan's in-depth comparison of his experiences providing tutoring to school children during the pandemic and his undergraduate teaching. He highlights the lack of learning resources for PGRs to draw on. These papers demonstrate tangibly how the pandemic has facilitated a reflection and evaluation of existing teaching practices.

It is particularly welcoming then to see such honesty and openness in the papers in this volume. To further humanise the experiences contained within this first volume and a sense of belonging to a discussion, we have made authorial ownership of each piece especially clear by including a full title page for each piece, including a short biography and a picture of our contributor. It is hoped 
that this would facilitate a sense of community, honestly, and of personal reflection - that this article was written by a real person undertaking their own journey of professional development that we might be able to reach out and talk to. We were especially pleased with how many of our articles open with a first-person pronoun. The authorial 'I' bedevils undergraduate writing; its presence has been criticised as arrogant, while its suppression 'may result in the apparency of objectivity, but it does not change opinion into revelation' (Raymond, 1993; Halmos, 1970;

Palmer 2017). For our purposes we felt clear that it was necessary to stress the subjective perspective of our contributors that were being reported to us. PGRs should be able to articulate who they are as a teacher, as expected in professional academic development programmes. It is particularly important to empower PGR teachers.

Furthermore, only with that context might we, the wider PGR community, learn from their experiences through reflection and contrast with our own experiences (Ajjawi and Boud 2018).

This is particularly effective in in Daniella and Pierre Botcherby's pieces which capture especially well the lived experience of adapting teaching during the pandemic. Both report their feelings and responses to the challenges they faced in a way that we hope will be hugely encouraging to prospective and seasoned teachers alike. Throughout Pierre's account are a smattering of helpful pointers towards facilitating a sense of community through Teams (and he is also particularly helpfully playful with the content and format of his article, including diagrams and bullet points, demonstrating the sort of range of possibilities that the JPPP might accommodate). The importance of this 'socialaffective dimension' (Carless 2013) and an 'online pedagogy of care' (Burke and Larmar 2020) for undergraduate learning is brilliantly explored and evidenced by Lindy Rudd and her exploration of how she promoted student interaction during the migration to online learning. Similarly, there is a real tangible concern and care that Giulia Lorenzi brings to her narrative, where she reflects on her teaching and the consequences of an inequality in the capacity of her students to access online learning resources. These papers in particular have a humour and informality which lends itself to their accessibility. There is also perhaps an interesting tension between lan's suggestion that online learning might allow greater and more economical access to higher education learning activities, and Giulia's concern for equitability of access to the same degree of learning opportunities.

In our Call for Papers, we indicated we would be welcome to more substantial, original evidence-based research. We were therefore particularly pleased to include the preliminary results of the survey of PGR support of the Warwick PTC team by Kate Lewis. These make interesting reading and are a helpful contrast to the more vignette details, case studies, and experiences reported in the other narratives included. To assist this contrast, in the future, we would hope to gain reflections and responses to previously published articles, and support an ongoing dialogue. The quantitative impressions from the surveys and the qualitative discourse it can generate may be of particular interest to those who support the personal and professional development of PGRs. Our volume closes with an afterword from Sara Hattersley, who reflects on the challenges of supporting teaching and learning online and the persistence of PGRs who teach during the pandemic.

\section{Future and Legacy}

It was recognised very early on that the journal and the wider Teaching Community had some particularly ambitious goals. The team therefore put into place various contingencies to provide scaled back versions of the larger initiatives. The success of the Warwick PTC in its earliest stages will be reviewed more fully elsewhere. In the early plans to create a community of practice, the project was primarily concerned with developing architecture and a legacy and to 
point towards future directions of development.

Initially, we anticipated reviewing interest in the journal after this issue to consider its viability. With the number and quality of submissions and their thoughtful reflections, we hope we have begun something of a dialogue. It opens up the possibility of further issues in the future. But volunteers will be needed to help support this dialogue. This might include the establishment of a more formal editorial board as part of the wider teaching community, perhaps along the line of executive of university societies. University societies are essentially fantastic examples of self-sustaining, entirely studentcreated spaces, beyond 'co-creation'. Support alternatively might be forthcoming from WIHEA, the Academic Development Centre, or Warwick Library to provide postgraduate representatives the opportunity to continue to act as Postgraduate Teaching Champions and to continue to try and facilitate community work. This sort of social nucleus and community spirit seems to be extremely ephemeral in other projects to support PGRs.

We hope that this might facilitate the discussion, informally and formally, of postgraduate teaching practice and pedagogy. It might lead to future surveys, newsletters, reading groups, conferences and symposia, social events, and other initiatives. With luck, this volume may contribute to that process. I hope you enjoy the papers!

\section{Acknowledgements}

Thank you so much to Pierre, Joy, and the rest of Warwick PTC team, and particularly Sara for all her help, from all of us. Thanks also to Matt Harwood, Sophie Pain, and the support of the Academic Development Centre and WIHEA.

\section{References}

Ajjawi, Rola, and David Boud. 2018.

"Examining the nature and effects of feedback dialogue." Assessment \& Evaluation in Higher Education 43 (7) 1106-19. doi:

10.1080/02602938.2018.1434128.

Bandura, Albert. 1993. "Perceived Self-Efficacy in Cognitive Development and Functioning." Educational Psychologist 28 (2):117-48. doi: 10.1207/s15326985ep2802_3.

Burke, Katie, and Stephen Larmar. 2020. "Acknowledging another face in the virtual crowd: Reimagining the online experience in higher education through an online pedagogy of care." Journal of Further and Higher Education: 1-15. doi: 10.1080/0309877X.2020.1804536.

Carless, David. 2013. "Trust and its role in facilitating dialogic feedback." In Feedback in Higher and Professional Education :

Understanding It and Doing It Well, edited by
David Boud and Elizabeth Molloy. Oxon: Routledge.

Chatterjee, Ritushree, and Ana-Paula Correia. 2020. "Online Students' Attitudes Toward Collaborative Learning and Sense of Community." American Journal of Distance Education 34 (1):53-68. doi: 10.1080/08923647.2020.1703479.

Chiu, Pit Ho Patrio and Paul Corrigan. 2019. "A study of graduate teaching assistants' selfefficacy in teaching: Fits and starts in the first triennium of teaching." Cogent Education, 6 (1) doi: 10.1080/2331186X.2019.1579964

Crossman, Joanna. 2007. "The role of relationships and emotions in student perceptions of learning and assessment." Higher Education Research \& Development 26 (3):313-27. doi: 10.1080/07294360701494328.

Fung, Dilly. 2021. "Foreword: Fresh Air for Graduate Teaching Assistants." Postgraduate Pedagogies 1. 


\section{Journal of PGR Pedagogic Practice}

Guthrie, Susan, Catherine A. Lichten, Janna van Belle, Sarah Ball, Anna Knack, and Joanna Hofman. 2017. "Understanding mental health in the research environment: A Rapid Evidence Assessment." RAND Corporation.

Halmos, Paul R. (1970). "How to Write Mathematics.". L'Enseignement mathématique. 16 (2): 123-152

Hilsdon, John. 2014. "Peer learning for change in higher education." Innovations in Education and Teaching Internationa/ 51 (3):244-54. doi: 10.1080/14703297.2013.796709.

Miralles-Armenteros, Sandra, Ricardo ChivaGómez, Alma Rodríguez-Sánchez, and Zina Barghouti. 2021. "Mindfulness and academic performance: The role of compassion and engagement." Innovations in Education and Teaching International 58 (1):3-13. doi: 10.1080/14703297.2019.1676284.

Palmer, Parker J. 2017. The Courage to Teach: Exploring the inner landscape of a teachers life: twentieth anniversary edition. San Fransico: Wiley.

Schussler, Elisabeth E., Quentin Read, Gili Marbach-Ad, Kristen Miller, and Miriam Ferzli. 2015. “Preparing Biology Graduate Teaching
Assistants for Their Roles as Instructors: An Assessment of Institutional Approaches." CBE-Life Sciences Education 14 (3).

Steen-Utheim, Anna, and Anne Line Wittek. 2017. "Dialogic feedback and potentialities for student learning." Learning, Culture and Social Interaction 15:18-30. doi: https://doi.org/10.1016/j.Icsi.2017.06.002.

University and College Union. 2021. "Postgraduate researchers as staff: Manifesto 2021."

University of Warwick. 2018. "Education Strategy: Learning beyond boundaries." University of Warwick.

University of Warwick. 2021. “Warwick named University of the Year for Teaching Quality".

Press Release. <

https://warwick.ac.uk/newsandevents/pressrele ases/warwick_named_university> [Accessed 17 September 2021].

Yang, Min, and David Carless. 2013. "The feedback triangle and the enhancement of dialogic feedback processes." Teaching in Higher Education 18 (3):285-97. doi: 10.1080/13562517.2012.719154.

To cite this article: Josh Patel, 2021 "The Journal of PGR Pedagogic Practice and the Warwick Postgraduate Teaching Community: Editorial." Journal of PGR Pedagogic Practice, 1, 3-9. Available at: [url] 